\title{
Health Consequences of Sarcopenic Obesity: A Narrative Review
}

\author{
Eun Roh and Kyung Mook Choi* \\ Division of Endocrinology and Metabolism, Department of Internal Medicine, Korea University College of Medicine, Seoul, \\ South Korea
}

Sarcopenia is defined as the age-related loss of muscle mass and strength or physical performance. Increased amounts of adipose tissue often accompany sarcopenia, a condition referred to as sarcopenic obesity. The prevalence of sarcopenic obesity among adults is rapidly increasing worldwide. However, the lack of a universal definition of sarcopenia limits comparisons between studies. Sarcopenia and obesity have similar pathophysiologic factors, including lifestyle behaviors, hormones, and immunological factors, all of which may synergistically affect the risk of developing a series of adverse health issues. Increasing evidence has shown that sarcopenic obesity is associated with accelerated functional decline and increased risks of cardiometabolic diseases and mortality. Therefore, the identification of sarcopenic obesity may be critical for clinicians

OPEN ACCESS

Edited by:

Andrea P. Rossi,

Integrated University Hospital

Verona, Italy

Reviewed by:

Valentina Muollo,

University of Verona, Italy

Ellen Freiberger.

University of Erlangen

Nuremberg, Germany

Tae Nyun Kim,

Inje University Haeundae Paik

Hospital, South Korea

*Correspondence:

Kyung Mook Cho

medica7@gmail.com

Specialty section:

This article was submitted to

Obesity,

a section of the journa

Frontiers in Endocrinology

Received: 28 January 2020

Accepted: 28 April 2020

Published: 21 May 2020

Citation:

Roh E and Choi KM (2020) Health Consequences of Sarcopenic Obesity:

A Narrative Review.

Front. Endocrinol. 11:332.

doi: 10.3389/fendo.2020.00332 in aging societies. In this review, we discuss the effect of sarcopenic obesity on multiple health outcomes and its role as a predictor of these outcomes based on the components of sarcopenia, including muscle mass, muscle strength, and physical performance.

Keywords: aging, sarcopenia, obesity, lean body mass, muscle strength, morbidity

\section{INTRODUCTION}

Sarcopenia is a condition characterized by the loss of muscle mass and strength or physical function that naturally occurs with aging. Cachexia is another cause of loss of muscle mass that occurs in diseases such as cancer or immunodeficiency diseases. Baumgartner was the first to propose the term sarcopenic obesity (1), defined as sarcopenia accompanied by an increase in the amount of adipose tissue. A confluence of two epidemics affects this condition: namely, an aging population and an increasing rate of obesity. Sarcopenia and obesity share common pathophysiologic mechanisms, including lifestyle behaviors, hormones, and immunological factors, all of which may act synergistically to affect the risk of developing a series of adverse health consequences. A longitudinal study reported that visceral obesity resulted in a loss of skeletal muscle mass (2). Thus, obesity and sarcopenia may act synergistically, and sarcopenic obesity may have a greater effect on metabolic disorders, cardiovascular disease (CVD), and mortality than either obesity or sarcopenia alone. In this review, we assessed the health consequences of sarcopenic obesity, particularly in age- and obesity-related metabolic diseases. Due to heterogeneity in the definitions and classifications of sarcopenic obesity, we also discuss the role of sarcopenic obesity as a predictor of multiple health outcomes according to each component of sarcopenia, including muscle mass, muscle strength, and physical performance.

\section{DEFINITION OF SARCOPENIC OBESITY}

The current definitions of sarcopenic obesity are based on the individual definitions of sarcopenia and obesity. However, these definitions vary considerably, causing difficulties in making an accurate 
diagnosis, performing epidemiologic studies, and developing treatment strategies for this disease. Our previous study assessed the ratio of visceral fat to thigh muscle area, which is associated with metabolic syndrome, as a single indicator reflecting sarcopenic obesity (3).

\section{Definition of Sarcopenia}

There remains no consensus regarding the appropriate cutoff points for sarcopenia. Baumgartner et al. first defined sarcopenia as an appendicular lean muscle mass (ALM) divided by height $^{2}$ less than two standard deviations (SDs) below the mean of a young reference group, as measured via dual X-ray absorptiometry (DXA) (4). Janssen et al. used skeletal muscle mass index $(\mathrm{SMI}=$ skeletal muscle mass/body mass $\times 100)$ measured via bioimpedance analysis (BIA) to define sarcopenia in older Americans (5). Newman et al. evaluated two definitions of sarcopenia in the Health, Aging and Body Composition (Health ABC) Study, which were as follows: ALM divided by height $^{2}$ and ALM divided by height and fat mass (6). They reported that the definition proposed by Baumgartner (ALM divided by height ${ }^{2}$ ) was strongly correlated to body mass index (BMI) and could therefore identify few individuals with sarcopenic obesity. In 2006, Newman et al. showed that muscle strength has a more important role than muscle mass in assessing mortality (7). Moreover, they reported that handgrip strength can provide risk estimates like those provided by quadriceps strength. The concept of dynapenia, a condition characterized by a decline in muscle strength with aging, was proposed in 2008 (8), and its significance in assessing muscle strength was subsequently highlighted $(9,10)$.

In 2010, the European Working Group for the Study of Sarcopenia (EWGSOP) (11) required the presence of both low muscle mass and low muscle function (strength or performance) for the diagnosis of sarcopenia. They recognized that muscle strength is not based solely on muscle mass and that the relationship between strength and mass is bidirectional rather than linear (12, 13). Moreover, older adults show a nonlinear relationship between leg strength and gait speed; these results provide a mechanism by which small changes in muscle strength produce large effects on physical performance (as assessed by gait speed) in frail adults (14). Thus, the EWGSOP has developed a suggested algorithm for sarcopenia screening using a gait speed of $<0.8 \mathrm{~m} / \mathrm{s}$ before the measurement of muscle mass or strength. The International Working Group for the Study of Sarcopenia provided a consensus definition for sarcopenia: namely, the combination of low appendicular lean mass and poor physical functioning (gait speed $<1$ $\mathrm{m} / \mathrm{s}$ ) (15). Moreover, they have indicated that patients with a habitual gait speed $<1.0 \mathrm{~m} / \mathrm{s}$ should be considered for the quantitative measurement of body composition using DXA. The Foundation for the National Institutes of Health (FNIH) Sarcopenia Project (16) reported an indirect but causal relationship between muscle mass and function based on their definition of sarcopenia. The FNIH recommended the assessment of low lean muscle mass (ALM: $<19.75 \mathrm{~kg}$ for men and $<15.02 \mathrm{~kg}$ for women) using DXA and reduced muscle function ( $<26 \mathrm{~kg}$ for men and $<16 \mathrm{~kg}$ for women) by handgrip, with adjustment for sex-specific cutoff points according to BMI (ALM/BMI cutoff values: $<0.789$ for men and $<0.512$ for women; grip strength/BMI cutoff values: $<1.0$ for men and $<0.56$ for women). Moreover, the organization consciously avoided the use of the term sarcopenia to differentiate qualitative (strength) and quantitative (mass) components and showed that individuals with poor physical function require different interventions according to the criteria of sarcopenia (low mass or low strength). In our study, appendicular skeletal muscle (ASM)/BMI-defined sarcopenia was more closely related to cardiometabolic risk factors than was $\mathrm{ASM} /$ height $^{2}$ or thigh muscle cross-sectional area (tmCSA)/weight-defined sarcopenia (17). The Asian Working Group for Sarcopenia proposed a diagnostic algorithm based on the evidence currently available in Asia (18). This group followed the EWGSOP approach for the definition of sarcopenia (low muscle mass plus low muscle strength and/or physical performance). However, unlike the method used by the EWGSOP, they included handgrip strength and gait speed in the initial screening. They provided different cutoff points for low muscle mass using DXA (ALM $/ \mathrm{ht}^{2}$ : $<7.0 \mathrm{~kg} / \mathrm{m}^{2}$ in men and $<5.4 \mathrm{~kg} / \mathrm{m}^{2}$ in women) or BIA (ALM $/ \mathrm{ht}^{2}:<7.0 \mathrm{~kg} / \mathrm{m}^{2}$ in men and $<5.7 \mathrm{~kg} / \mathrm{m}^{2}$ in women), low muscle strength using handgrip strength $(<26 \mathrm{~kg}$ for and $<18 \mathrm{~kg}$ for women), and low physical performance using gait speed $(<0.8 \mathrm{~m} / \mathrm{s})$.

In 2018, the updated EWGSOP2 aimed to increase the early detection and treatment of sarcopenia and its risk in clinical practice (19). The group adopted low muscle strength as a principal determinant of sarcopenia because muscle strength is considered better than muscle mass in predicting adverse outcomes (20-22). The EWGSOP2 focused on low muscle strength (grip strength) as the primary parameter of sarcopenia, used low muscle quantity and quality to confirm the sarcopenia diagnosis (DXA or alternatives), and suggested measures of physical performance (gait speed or Timed Up and Go test) to assess the severity of sarcopenia.

\section{Definition of Obesity}

Obesity is a chronic metabolic disease characterized by an increase in body fat stores that consequently elevates the risk of metabolic diseases, CVD, and mortality. As with sarcopenia, a consensus is currently lacking regarding the appropriate cutoff points for obesity. The World Health Organization (WHO) uses BMI to define obesity $\left(\geq 30 \mathrm{~kg} / \mathrm{m}^{2}\right)$ and overweight $(25-$ $29.9 \mathrm{~kg} / \mathrm{m}^{2}$ ) (23). East Asians generally have higher body fat percentages than non-Asians at the same BMI (24). Thus, East Asians have lower BMI cutoff points for obesity $\left(\geq 25 \mathrm{~kg} / \mathrm{m}^{2}\right)$ and overweight $\left(23-24.5 \mathrm{~kg} / \mathrm{m}^{2}\right)$ (25). Although BMI is a useful indicator of body fat in clinical practice, body fat distribution has a better predictive ability than BMI for the development of metabolic syndrome and risk of CVD (26). The American Association of Clinical Endocrinology (27) recommends the use of the WHO body fat thresholds for the diagnosis of obesity ( $>25 \%$ in men and $>35 \%$ in women). The amount of abdominal fat is easily assessed using waist circumference (WC), which is highly correlated to intra-abdominal fat content. The WHO also used WC thresholds (men: $\geq 102 \mathrm{~cm}$ and women: $\geq 88 \mathrm{~cm}$ ) as a 
surrogate for visceral fat. Lower cutoff points for central obesity are required for different ethnic groups, including Asians (28). The recommended cutoffs are $\geq 90$ and $\geq 80 \mathrm{~cm}$ in Asian men and women, respectively. The Korean Society for the Study of Obesity defines abdominal obesity as WC $\geq 90$ and $\geq 85 \mathrm{~cm}$ in men and women, respectively, based on epidemiologic study findings (29).

\section{PREVALENCE OF SARCOPENIC OBESITY}

Accurate estimation of the prevalence of sarcopenic obesity is limited due to not only the lack of a universally adopted definition of sarcopenia but also the use of different body composition assessment techniques (30). In a 14-year prospective study of older adults $(n=4,652)$ more than 60 years of age by the National Health and Nutrition Examination Survey (NHANES) III, the prevalence rates of sarcopenic obesity were $18.1 \%$ in women and $42.9 \%$ in men (31). The study defined sarcopenia using the BIA-derived sex-specific cutoffs for ALM $/ \mathrm{ht}^{2}$, as proposed by Janssen et al. (13) (men: $\leq 10.75 \mathrm{~kg} / \mathrm{m}^{2}$ and women: $\leq 6.75$ $\mathrm{kg} / \mathrm{m}^{2}$ ). Obesity was based on the percentage of body fat (men: $\geq 27 \%$, women: $\geq 38 \%$ ). Previous studies in Korea have assessed the prevalence rates of sarcopenic obesity using information from the Korean NHANES (KNHANES) IV $(32,33)$ database, which measured skeletal muscle mass using DXA. The prevalence rate of sarcopenic obesity was $7.6 \%$ for men and $9.1 \%$ for women based on ALM/weight (\%). However, the rate was nearly zero for men and women using the $\mathrm{ALM} / \mathrm{ht}^{2}$ definition in the elderly population aged $\geq 65$ years (32). Sarcopenic obesity was defined as class II sarcopenia with central obesity (WC: $\geq 90 \mathrm{~cm}$ for men and $\geq 85 \mathrm{~cm}$ for women) (29). Another study in Koreans $(n=2,221)$ aged over 60 years that used the same definition of sarcopenic obesity (ALM/weight (\%): <2 SD from the reference values of young adult and central obesity) reported a prevalence rate of sarcopenic obesity of $6.1 \%$ for men and $7.3 \%$ for women (33). The rapidly increasing prevalence of obesity suggests the likely corresponding increase in sarcopenic obesity in these individuals.

\section{HEALTH CONSEQUENCES OF SARCOPENIC OBESITY}

\section{Disability and Institutionalization}

Sarcopenic obesity is associated with disability. In a cohort study of 451 elderly men and women, subjects with sarcopenic obesity, defined according to ALM $/ \mathrm{ht}^{2}$ and percent body fat, had a 2.5-fold increased risk of disability during an 8-year follow-up period than individuals without sarcopenic obesity (34); however, sarcopenia or obesity alone were not significantly associated with disability. The Concord Health and Aging Project reported that elderly men with sarcopenic obesity (defined based on ALM/BMI and \% body fat according to the FNIH criteria) had a 2-fold higher risk of frailty and an $\sim 1.5$-fold increased risk of disability during the 7 years of follow-up (35). Sarcopenia was associated with poor functional outcomes while obesity alone was not associated with any adverse outcomes. However, several crosssectional studies reported opposite or mixed results. Sarcopenia or sarcopenic obesity (low muscle mass and high \% body fat) was not related to disability in people aged 70 years and older from the NHANES, although obesity was associated with an increased risk of functional limitation in both men and women (36). Another study reported that elderly women with sarcopenia only or with sarcopenic obesity did not have increased risks of disability, whereas those with obesity showed a 3 -fold increased risk of disability (37).

Growing evidence indicates that muscle strength is a better indicator of aging-related functional decline than muscle mass. A meta-analysis of the relationship between body composition and muscle strength measures and functional decline in older men and women reported an association between dynapenia and obesity and long-term functional decline, respectively (20). In contrast, low muscle mass was not significantly associated with functional limitations. In the Invecchiare in Chianti (InCHIANTI, aging in the Chianti area) study, communitydwelling older adults with dynapenic obesity showed a steeper decline in walking speed and an increased risk of developing new mobility disability over the 6-year follow-up compared to those without obesity or dynapenia (38). A cross-sectional study from China found that dynapenic obesity (low handgrip strength and elevated BMI) was associated with increased risks of disability and slow gait speed compared to either dynapenia or obesity alone in an older Asian population (39). Similarly, a 2-year follow-up longitudinal study from Japan reported a higher risk of developing mobility limitations in older women with dynapenic obesity than in participants without dynapenia or obesity (40). Obesity alone was not associated with the incidence of mobility limitations. Data from the UK Biobank study recently showed that high BMI and low grip strength at baseline independently predicted lower physical activity levels as assessed by wrist-worn accelerometry at follow-up (41).

Physical performance, one of the components of sarcopenia, has predictive value for disability. Decreased physical performance, as assessed by gait speed, increased the risk of disability in elderly people (42). Another prospective cohort study of Health $A B C$ participants showed increased risks of functional limitation and mortality in participants with slow gait speed (43). Furthermore, other tests of lower extremity function such as chair stand and standing balance showed comparable prognostic value for adverse health events.

Each component of sarcopenia has a different association with institutionalization. A large observational study using data from Health $\mathrm{ABC}$ participants found that low muscle mass was not independently associated with an increased risk of hospitalization (44). However, low muscle strength and poor physical performance were associated with increased risks of hospitalization (44). A Japanese population-based cohort study also reported that both low muscle strength and physical performance were risk factors for the certification of need of care (45). Moreover, physical performance measures such as gait speed have been associated with future hospitalization and institutionalization in a variety of populations (46-48). A recent prospective cohort study of patients with osteoporotic fractures found that none of the consensus definitions of sarcopenia nor the definition components of low muscle mass or low muscle 
strength was associated with increased risks of hospitalization or short-term nursing facility stay in older men and women. In contrast, the presence of slowness (based on gait speed) was associated with an increased likelihood of hospitalization (49, 50), although the association was attenuated after adjusting for confounding factors in men (49).

Few longitudinal studies have evaluated the relationship between sarcopenic obesity and institutionalization. Among elderly men in the Concord Health and Aging Project, low muscle mass and sarcopenic obesity (defined based on ALM/BMI and $\%$ body fat according to FNIH criteria) were not associated with institutionalization (35). However, the association between obesity and hospitalization or institutionalization is more obvious. For instance, participants with obesity (BMI $\geq 30 \mathrm{~kg} / \mathrm{m}^{2}$ ) in the NHANES showed a higher likelihood of nursing facility use (51). A longitudinal observation study reported midlife obesity to be associated with an increased risk of nursing home admission in late life (52), an association that persists in older adults with obesity (53). A similar association was shown in a Japanese population-based cohort study that reported an increased risk of certification of need of care in older adults with obesity (BMI $\left.\geq 27.5 \mathrm{~kg} / \mathrm{m}^{2}\right)(45)$.

\section{Mortality}

Several prospective studies have investigated the relationship between sarcopenic obesity and the risk of mortality. However, the definitions of both sarcopenia and obesity vary across studies and the results have been conflicting. The British Regional Heart Study, a 6-year prospective study of 4,252 men aged 60-79 years, reported a $55 \%$ higher risk of mortality in men with a high WC $(>102 \mathrm{~cm})$ and low midarm muscle circumference (sarcopenic obesity) than in those without sarcopenia or obesity (54). Furthermore, in the extended 11-year follow-up of the British Regional Heart Study, men with sarcopenic obesity had a higher all-cause mortality risk [hazard ratio (HR): 1.72, 95\% confidence interval (CI): 1.35-2.18] than those with sarcopenia without obesity (HR: 1.41, 95\% CI: 1.22-1.63) and non-sarcopenic obese men (HR: 1.21, 95\% CI: 1.03-1.42) (55). Another prospective study of 4,652 participants aged $\geq 60$ years from the NHANES III with a 14-year follow-up showed higher risks of all-cause mortality in women with sarcopenia (HR: 1.35, 95\% CI: $1.05-$ 1.74) and sarcopenic obesity (based on ALM/ht ${ }^{2}$ and body fat measurement from BIA) (HR: 1.29, 95\% CI: 1.03-1.60) than in women without sarcopenia or obesity (56). Meanwhile, women with obesity were not at a high risk of mortality, and no significant difference was observed in mortality risk in male participants with sarcopenia, obesity, and sarcopenic obesity. In contrast, the InCHIANTI study, which included 934 participants aged 65 years or older in their 6-year follow-up, reported no significant difference in mortality risks across six study groups according to calf skeletal muscle mass and BMI. However, individuals with sarcopenic obesity showed the lowest survival rate (57). Interestingly, low physical performance (measured using walking speed) was significantly associated with increased mortality in older adults (57). Recently, a long-term follow-up study of 2,309 Japanese-American elderly men from the Kuakini Honolulu Heart Program reported a significantly higher risk of mortality in the sarcopenia group (defined using ALM $/ \mathrm{ht}^{2}$ with DXA) than in the non-sarcopenia non-obesity group using all three definitions of obesity (BMI, \% body fat, and WC) (58). The risk of mortality was significantly higher in the sarcopenic obesity group defined using WC than in the non-sarcopenia non-obesity group (HR: 1.19, 95\% CI: 1.02-1.38) but not in the groups defined using BMI and \% body fat.

Measures of muscle strength, both knee extension and grip, were strong and independent predictors of mortality in older adults (7). The magnitude of association for both quadriceps and grip strength were similar (7). Although leg strength was more strongly associated with age itself than has grip strength $(59,60)$, grip strength is currently much easier to measure, thus has greater potential for incorporating into clinic practice. A growing body of evidence indicates that muscular strength, as measured using grip strength, is associated with a variety of health outcomes including mortality in older adults (61-65). Moreover, lower handgrip strength was correlated with increased risks of all-cause mortality (HR: 1.41, 95\% CI: 1.30-1.52) and CVDs (HR: 1.63, 95\% CI: 1.36$1.96)$ in a recent meta-analysis of 42 prospective cohort studies that included 3,002,203 participants (66). In a prospective study of 6,040 healthy men aged 45-68 years who were followed-up for over 30 years, adult men with the lowest tertile of handgrip strength at baseline had a higher risk for mortality, independent of BMI (67). Another prospective study from Taiwan reported a higher risk of mortality in participants with dynapenia without obesity than in those with obesity alone and even those with dynapenic obesity (defined using grip strength and WC) (68). Thus, dynapenia rather than obesity may have caused the unfavorable impact of dynapenic obesity. A similar observation was reported in a 33-year follow-up study that included 3,594 men and women aged 50-91 years from the Mini-Finland Health Examination Survey. In this study, among participants aged $\geq 70$ years, the risk of mortality was higher in participants with dynapenic obesity (defined using grip strength and BMI) (HR: 1.23, 95\% CI: 1.04-1.46) and dynapenia alone (HR: 1.30, 95\% CI: 1.09-1.54) than in participants without dynapenia or obesity (69). Moreover, the English Longitudinal Study of Aging reported minimal differences in all-cause mortality between patients with dynapenic obesity (defined using grip strength and BMI) and those with dynapenia alone (70). In this study, weight loss combined with low muscle strength had the greatest risk of mortality. Likewise, recent studies have shown an association between overweight or obesity and a lower risk of CVD or CVD-associated death, whereas being underweight is associated with an increased risk of CVD, a phenomenon known as the obesity paradox $(71,72)$. Furthermore, several prospective studies reported a J-shaped association between BMI and both all-cause and cardiovascular mortality $(73,74)$. One possible explanation for the obesity paradox may be that overweight or obesity is associated with increased levels of lean mass (75). Older people with weight loss lose a greater percentage of lean mass than fat mass (76), which could contribute to the increased risk of CVD events after weight loss.

Slow walking speed in older people was associated with an increased risk of cardiovascular mortality in a cohort of 3,208 older men and women (77). Moreover, gait speed was associated 
with survival in pooled analysis of individual data from 9 cohort studies (pooled HR per $0.1 \mathrm{~m} / \mathrm{s}: 0.88,95 \%$ CI: $0.87-0.90, P<$ 0.001) (78). Short Physical Performance Battery (SPPB) score is a group of physical performance measures including gait speed, chair rises, and balance test, and it was associated with an increased risk of all-cause mortality in a meta-analysis (79). A comparative study among 3,099 older community-dwelling men and women revealed that slow gait speed and low SPPB scores were significant predictors for mortality, and the prognostic usefulness of SPPB and gait speed were similar, independently from gender (80). However, there is no study that evaluated the synergistic effects of low physical performance and obesity.

\section{Metabolic Diseases}

Both sarcopenia and obesity are associated with metabolic disorders (81). Thus, sarcopenic obesity may have a greater impact on metabolic diseases and CVD-associated mortality than either sarcopenia or obesity alone (82-85). In a large cross-sectional analysis of 14,528 adults from the NHANES III, the sarcopenic obesity group (defined based on BIAmeasured muscle mass and BMI) showed the highest risk of insulin resistance and dysglycemia (86). The Korean Sarcopenic Obesity Study (KSOS) cohort study showed that sarcopenic obesity [defined using DXA-measured ALM/weight (\%) and visceral fat area] was associated with insulin resistance [Homeostatic Model Assessment of Insulin Resistance (HOMAIR) score], inflammation (C-reactive protein level), and vitamin D deficiency (87). A cross-sectional study of 2,943 participants aged 60 years or older from KNHANES also reported that sarcopenic obesity [based on DXA-measured ALM/weight (\%) and BMI] was associated with insulin resistance, metabolic syndrome, dyslipidemia, and vitamin D deficiency (88). Lim et al. observed a higher risk of metabolic syndrome among adults with sarcopenic obesity [defined using DXA-measured ALM/weight (\%) and visceral fat area] [odds ratio (OR): 8.28, 95\% CI: 4.45-15.40] than among those with obesity (OR: 5.51, 95\% CI: 2.81-10.80) or sarcopenia (OR: $2.64,95 \%$ CI: $1.08-$ 6.44) in a cross-sectional study of 565 participants aged $\geq 65$ years from the Korean Longitudinal Study on Health and Aging (89). In contrast, using the definition ALM/ht ${ }^{2}$, the ORs of metabolic syndrome were lower in the obesity group than in the sarcopenic obesity group (2.90 [95\% CI: $1.28-6.57]$ vs. 4.80 [95\% CI: 2.63-8.75]) (89). Similar findings were reported in a study of 600 community-dwelling older adults from Taiwan, in which sarcopenic obesity [defined based on BIA-measured ALM/weight (\%) and BMI] was associated with the highest risk of metabolic syndrome (90). The sarcopenic obesity group had a higher risk of metabolic syndrome (OR: 11.59, 95\% CI: $6.72-19.98$ ) than the obesity group (OR: $7.53,95 \%$ CI: $4.01-$ 14.14) and sarcopenia group (OR: 1.98, 95\% CI: 1.25-3.16). Our study comparing Australian and Korean populations observed a potential difference in the effects of low muscle mass on the risk of metabolic syndrome according to ethnicity (91).

Several cross-sectional studies of Korean populations of older adults from the KNHANES database reported sarcopenic obesity to be more strongly associated with increased risks of hypertension, dyslipidemia, and diabetes than sarcopenia or obesity alone (92-94). These studies defined sarcopenia as ALM/weight (\%) since the association between sarcopenic obesity and cardiometabolic parameters was not definite when sarcopenia was indicated as ALM/ht ${ }^{2}$. The risk of hypertension was higher in the sarcopenia (OR: 2.48, 95\% CI: 1.89-6.16), obesity (OR: 3.15, 95\% CI: 2.76-3.59), and sarcopenic obesity (OR: 6.42, 95\% CI: 4.85-8.48) groups than in the non-sarcopenia non-obesity group [defined using DXA-measured ALM/weight (\%) and WC]. Furthermore, individuals with sarcopenic obesity [defined based on DXA-measured ALM/weight (\%) and BMI] had a higher risk of dyslipidemia (OR: 2.82, 95\% CI: 1.76-4.51) than men in the obesity (OR: $2.12,95 \%$ CI: $1.11-4.07$ ) and sarcopenia (OR: 1.46, 95\% CI: 1.01-2.11) groups (92). Another Korean study reported a higher risk of diabetes in the sarcopenic obesity group [defined using DXA-measured ALM/weight (\%) and WC] (OR: 2.16, 95\% CI: 1.08-3.27) than in the sarcopenia group (OR: 1.24, 95\% CI: 0.86-2.15) (93). Considering the association between sarcopenia and cardiometabolic risk factors, a cross-sectional study was performed to assess the association between sarcopenic obesity and the risk of CVD in Korean adults from the KNHANES database. The 10-year CVD risk of the participants was estimated using the Framingham risk score. The sarcopenic obesity group [based on the DXA-measured ALM/weight (\%) and BMI] had a higher 10-year CVD risk than the non-sarcopenia non-obesity group (OR: 2.49 , 95\% CI: $1.53-$ 4.06 in men; OR: 1.87 ; $95 \%$ CI: $1.02-3.41$ in women) (94). In contrast, the risk of CVD was not high in the groups with sarcopenia or obesity alone.

However, studies on the relationship between sarcopenic obesity and CVD have reported contrasting results. A prospective cohort study of older men from the British Regional Heart Study did not observe increased risks of coronary heart disease (fatal or non-fatal myocardial infarction) or CVD (non-fatal myocardial infarction, non-fatal stroke, or fatal CVD) events in men with sarcopenic obesity (defined based on WC and midarm muscle circumference) (55). These men were at a higher risk of CVDassociated mortality. However, the risk was not significant in the adjusted model and was similar to that of individuals with sarcopenia or obesity alone. Moreover, several cross-sectional studies have reported that older adults with sarcopenic obesity [based on DXA-measured ALM/weight (\%) and \% body fat or BMI] did not have a significantly higher prevalence of CVD than adults without sarcopenia or obesity $(34,95-97)$.

Recent studies have investigated the relationship between low muscle strength and metabolic diseases. Relative handgrip strength, defined as handgrip strength normalized for BMI, was strongly negatively correlated with metabolic syndrome (98), hypertension (99), and dyslipidemia (100). Handgrip strength normalized by body weight was inversely associated with insulin resistance and type 2 diabetes (101). Furthermore, lower handgrip strength was associated with non-alcoholic fatty liver disease (102) and all-cause and CVD mortality (103). Some studies have reported an association between dynapenic obesity and metabolic disorders. A longitudinal study of 5,953 older adults from the English Longitudinal Study of Aging reported an association between dynapenic obesity (defined using grip strength and BMI) and an increased risk of type 2 
diabetes (OR: 3.57, 95\% CI: 2.04-6.24) (104). The Cardiovascular Health Study, a large prospective study of 3,366 communitydwelling older individuals, demonstrated an association between dynapenic obesity (based on handgrip strength and WC) and the highest risk of CVD (105). Compared to that in participants without sarcopenia or obesity, the risk of CVD did not significantly increase in the dynapenia or obesity groups. However, the risk of CVD increased by $23 \%$ in the dynapenia and obesity groups. In contrast, the risk of CVD was not significantly higher in the sarcopenic obesity group, when defined using BIAmeasured muscle mass; thus, muscle strength may be more important predictor of CVD than muscle mass.

Chronic medical conditions such as hypertension, diabetes mellitus, and dyslipidemia were associated with lower walking speed and greater decline in walking speed in older people $(106,107)$. Moreover, in a longitudinal cohort study of 5,376 adults without CVD, higher cardiovascular risk scores at baseline were associated with future risk of poor physical performance at approximately 16 years of follow-up (108). All these results indicated that midlife cardiovascular risk factors likely contribute to poor physical function and disability in the elderly.

\section{Comorbidities}

Low muscle mass and strength are associated with an increased fall risk in community-dwelling older adults. In elderly men, low muscle mass was associated with impaired balance and an increased risk of falls (109). A meta-analysis reported increased risks of any and recurrent falls in older adults with low muscle strength (110). Elderly individuals with sarcopenia as defined by the EWGSOP (low muscle mass plus either low muscle strength or low physical performance) were over three times more likely to fall during a 2-year follow-up period than individuals without sarcopenia (111). In contrast, a 5-year prospective cohort study that included 674 middle-aged and older adults reported an increased risk of falls in individuals with dynapenic obesity (based on trunk fat mass) but not in those with sarcopenic obesity (112). Consistently, dynapenic abdominal obesity (based on handgrip strength and WC) is associated with an increased risk of falls in older women; moreover, these relationships are stronger than those observed for obesity or dynapenia alone (113).

A cross-sectional study using data from 2,893 in KNHANES participants reported a high risk of knee osteoarthritis in the sarcopenic obesity [determined based on ALM/weight (\%) and BMI] (OR: 3.51, 95\% CI: 2.15-5.75) and non-sarcopenic obesity (OR: 2.38, 95\% CI: 1.80-3.15) groups but not in the sarcopenic non-obesity group (114). The risk of osteoporosis was higher in the sarcopenic obesity group (based on $\mathrm{ALM} / \mathrm{ht}^{2}$ and $\%$ body fat) (OR: 8.67, 95\% CI: 4.19-17.94 in men and OR: 2.93, 95\% CI: $1.99-4.32$ in women) (115). Similarly, another study that defined sarcopenic obesity as low muscle mass or muscle strength, with obesity defined according to fat mass, reported lower bone mineral density and a higher risk of non-vertebral fracture in older adults with sarcopenic obesity than in adults without sarcopenia, without obesity, and only obesity (116).

Several reports have shown the relationship between sarcopenic obesity and psychological health problems. A 6-year prospective study of 3,862 participants from the English
Longitudinal Study of Aging reported an increased risk of depression in patients with sarcopenic obesity (defined based on grip strength and BMI) (OR: 1.79, 95\% CI: 1.10-2.89) than in individuals without sarcopenia or obesity. The risk of depression was not significantly higher in participants with obesity or sarcopenia alone (117). Another study reported similar findings, showing that sarcopenic obesity-defined based on low muscle mass plus either low muscle strength or low physical performance, with obesity defined according to \% body fat-was positively associated with depressive symptoms compared with non-sarcopenic non-obesity (118). Sarcopenia or obesity alone were not associated with depressive symptoms.

\section{DISCUSSION}

Sarcopenic obesity is a global health phenomenon due to both the rapid increase in the number of elderly individuals and the obesity epidemic. Aging-associated increases in visceral fat and reduced muscle mass are correlated with multiple adverse cardiometabolic effects and contribute to poor health outcomes (119). Several biological pathways lead to age-related sarcopenic obesity. Aging lowers the resting metabolic rate and metabolic adaptation including adaptive thermogenesis, perpetuating low muscle mass, and increased body fat $(120,121)$. Reduced resting metabolic rate, physical activity, mitochondrial volume, and oxidative capacity with age contribute to aging-related decreases in muscle mass and strength (122-124). Moreover, the aging-related changes in body fat distribution include a loss of subcutaneous fat, accumulation of visceral fat, and ectopic fat deposition (125). Sex-specific hormonal changes are an important factor related to sarcopenic obesity. In women, declining estrogen levels after menopause result in increased body weight and fat mass as well as shifts in the accumulation of fat from subcutaneous to visceral deposits $(126,127)$. In older men, total testosterone levels decline by about $1 \%$ per year of age, with lower levels associated with sarcopenia, lower muscle strength, poorer physical performance, and increased fall risk (128-130). Randomized controlled trials of various formulations of testosterone supplementation in older men have reported improvements in body composition including increased lean body mass and reduced fat mass $(131,132)$. However, the effects of testosterone therapy on muscle strength or physical performance are conflicting. Increasing serum testosterone levels to low- to mid-normal ranges through the administration of testosterone for several months in healthy older men resulted in increased muscle strength (133-136) and improved physical performance $(134,135)$. In contrast, a randomized controlled trial of testosterone replacement for 6 months in healthy older men reported increased lean body mass and decreased fat mass, with no increase in functional mobility or muscle strength (137). Another study on testosterone supplementation for 1 year did not observe improved walking distance in older men with reduced testosterone levels (138).

Obesity in aged individuals stimulates sarcopenia by altering skeletal muscle lipid metabolism, insulin resistance, and inflammatory pathways (139-141). Obesity promotes 




\section{Aging / Obesity}

the deposition of ectopic fat into skeletal muscle, which can negatively affect sarcopenia (142, 143). Both intermuscular adipose tissue and intramuscular lipid metabolites can lead to marked impairment in mitochondrial fatty acid oxidation, increased lipolysis, and increased oxidative stress (141, 144, 145). These events can promote lipotoxicity, insulin resistance, and inflammation in skeletal muscle, resulting in decreased muscle mass and muscle fiber contractility $(141,146,147)$. Obesity-associated adipose tissue inflammation is another mechanism leading to sarcopenia (141). Obesity promotes inflammatory pathways in visceral fat through adipocyte hypertrophy and hyperplasia and the accumulation of immune cells including macrophages, mast cells, and $\mathrm{T}$ lymphocytes producing pro-inflammatory cytokines (148-150). Moreover, increased secretion of leptin from adipose tissue upregulates the production of pro-inflammatory cytokines such as tumor necrosis factor (TNF) $\alpha$ and interleukin (IL)-1 $\beta$ (151). Elevated $\mathrm{TNF} \alpha$ directly impairs adiponectin signaling, thus inhibiting mitochondrial biogenesis and myogenesis in human skeletal muscle cells (152). Pro-inflammatory cytokines can also negatively affect the anabolic action of insulin-like growth factor 1 (IGF1), resulting in an increased incidence of frailty in older men along with the age-related reduction in testosterone levels (153). All these changes can induce and/or exacerbate decreased skeletal muscle mass and function. The mechanisms of developing sarcopenic obesity with age was schematically depicted in Figure 1.

As sarcopenia and obesity share pathological factors including aging, hormones, and immunological factors, sarcopenic obesity affects the risks of adverse health outcomes more than sarcopenia or obesity individually. A growing body of evidence has shown the associations of sarcopenic obesity with increased risks of disability, institutionalization, mortality, metabolic diseases, CVD, and other comorbidities, compared to sarcopenia or obesity alone. However, the findings of studies on the relationship between sarcopenic obesity and cardiometabolic risk are discordant. The inconsistencies in the associations between sarcopenic obesity and health outcomes may be attributed to differences in sample sizes, study population characteristics, and heterogeneity in the definitions of sarcopenic obesity. Furthermore, the role of dynapenia, a condition characterized by an age-related decline in muscle strength, is now considered a principal determinant of sarcopenia, overtaking the role of low muscle mass $(20,21)$. Notably, the EWGSOP2 reported low muscle strength as a key characteristic of sarcopenia to facilitate the prompt identification of sarcopenia in practice (19). In this revised consensus, low physical performance is proposed as an indicator of severe sarcopenia. Physical performance involves 
not only muscles but also bones, balance, and cardiovascular capacity, beyond muscle function measures (154). Further studies to elucidate the molecular mechanisms of age-associated changes in muscle mass, muscle strength, and physical performance are needed to prevent and treat sarcopenia; these biological pathways should be considered along with age-associated obesity.

\section{AUTHOR CONTRIBUTIONS}

ER contributed to the literature search and original draft preparation. KC contributed to the study conceptualization and

\section{REFERENCES}

1. Baumgartner RN. Body composition in healthy aging. Ann N Y Acad Sci. (2000) 904:437-48. doi: 10.1111/j.1749-6632.2000.tb06498.x

2. Kim TN, Park MS, Ryu JY, Choi HY, Hong HC, Yoo HJ, et al. Impact of visceral fat on skeletal muscle mass and vice versa in a prospective cohort study: the Korean sarcopenic obesity study (KSOS). PLoS ONE. (2014) 9:e115407. doi: 10.1371/journal.pone.0115407

3. Lim KI, Yang SJ, Kim TN, Yoo HJ, Kang HJ, Song W, et al. The association between the ratio of visceral fat to thigh muscle area and metabolic syndrome: the Korean sarcopenic obesity study (KSOS). Clin Endocrinol. (2010) 73:588-94. doi: 10.1111/j.1365-2265.2010.03841.x

4. Baumgartner RN, Koehler KM, Gallagher D, Romero L, Heymsfield SB, Ross $\mathrm{RR}$, et al. Epidemiology of sarcopenia among the elderly in new Mexico. Am J Epidemiol. (1998) 147:755-63. doi: 10.1093/oxfordjournals.aje.a009520

5. Janssen I, Heymsfield SB, Ross R. Low relative skeletal muscle mass (sarcopenia) in older persons is associated with functional impairment and physical disability. J Am Geriatr Soc. (2002) 50:889-96. doi: 10.1046/j.1532-5415.2002.50216.x

6. Newman AB, Kupelian V, Visser M, Simonsick E, Goodpaster B, Nevitt $M$, et al. Sarcopenia: alternative definitions and associations with lower extremity function. J Am Geriatr Soc. (2003) 51:1602-9. doi: 10.1046/j.1532-5415.2003.51534.x

7. Newman AB, Kupelian V, Visser M, Simonsick EM, Goodpaster BH, Kritchevsky SB, et al. Strength, but not muscle mass, is associated with mortality in the health, aging and body composition study cohort. J Gerontol A Biol Sci Med Sci. (2006) 61:72-7. doi: 10.1093/gerona/61.1.72

8. Clark BC, Manini TM. Sarcopenia $\neq$ dynapenia. J Gerontol A Biol Sci Med Sci. (2008) 63:829-34. doi: 10.1093/gerona/63.8.829

9. Clark BC, Manini TM. Functional consequences of sarcopenia and dynapenia in the elderly. Curr Opin Clin Nutr Metab Care. (2010) 13:271-6. doi: 10.1097/MCO.0b013e328337819e

10. Russ DW, Gregg-Cornell K, Conaway MJ, Clark BC. Evolving concepts on the age-related changes in "muscle quality". J Cachexia Sarcopenia Muscle. (2012) 3:95-109. doi: 10.1007/s13539-011-0054-2

11. Cruz-Jentoft AJ, Baeyens JP, Bauer JM, Boirie Y, Cederholm T, Landi F, et al. Sarcopenia: European consensus on definition and diagnosis: report of the European working group on Sarcopenia in older people. Age Ageing. (2010) 39:412-23. doi: 10.1093/ageing/afq034

12. Goodpaster BH, Park SW, Harris TB, Kritchevsky SB, Nevitt M, Schwartz AV, et al. The loss of skeletal muscle strength, mass, and quality in older adults: the health, aging and body composition study. J Gerontol A Biol Sci Med Sci. (2006) 61:1059-64. doi: 10.1093/gerona/61.10.1059

13. Janssen I, Baumgartner RN, Ross R, Rosenberg IH, Roubenoff R. Skeletal muscle cutpoints associated with elevated physical disability risk in older men and women. Am J Epidemiol. (2004) 159:413-21. doi: 10.1093/aje/kwh058

14. Buchner DM, Larson EB, Wagner EH, Koepsell TD, de Lateur BJ. Evidence for a non-linear relationship between leg strength and gait speed. Age Ageing. (1996) 25:386-91. doi: 10.1093/ageing/25.5.386

15. Fielding RA, Vellas B, Evans WJ, Bhasin S, Morley JE, Newman AB, et al. Sarcopenia: an undiagnosed condition in older adults. Current text review and editing. All authors have read and agreed to the published version of the manuscript.

\section{FUNDING}

KC was funded by the Korea University Research Fund (B1901301, A920197507). ER was funded by the Basic Science Research Program through the National Research Foundation of Korea (NRF) funded by the Ministry of Education (2018R1D1A1B07050991) and by the Korea University Guro Hospital Grant (O1903891). consensus definition: prevalence, etiology, and consequences. International working group on sarcopenia. J Am Med Dir Assoc. (2011) 12:249-56. doi: 10.1016/j.jamda.2011.01.003

16. Studenski SA, Peters KW, Alley DE, Cawthon PM, McLean RR, Harris TB, et al. The FNIH sarcopenia project: rationale, study description, conference recommendations, and final estimates. J Gerontol A Biol Sci Med Sci. (2014) 69:547-58. doi: 10.1093/gerona/glu010

17. Kim TN, Park MS, Lee EJ, Chung HS, Yoo HJ, Kang HJ, et al. Comparisons of three different methods for defining sarcopenia: an aspect of cardiometabolic risk. Sci Rep. (2017) 7:6491. doi: 10.1038/s41598-017-06831-7

18. Chen L-K, Liu L-K, Woo J, Assantachai P, Auyeung T-W, Bahyah $\mathrm{KS}$, et al. Sarcopenia in Asia: consensus report of the Asian working group for sarcopenia. J Am Med Dir Assoc. (2014) 15:95-101. doi: 10.1016/j.jamda.2013.11.025

19. Cruz-Jentoft AJ, Bahat G, Bauer J, Boirie Y, Bruyère O, Cederholm T, et al. Sarcopenia: revised European consensus on definition and diagnosis. Age Ageing. (2019) 48:16-31. doi: 10.1093/ageing/afy169

20. Schaap LA, Koster A, Visser M. Adiposity, muscle mass, and muscle strength in relation to functional decline in older persons. Epidemiol Rev. (2013) 35:51-65. doi: 10.1093/epirev/mxs006

21. Leong DP, Teo KK, Rangarajan S, Lopez-Jaramillo P, Avezum A, Orlandini A, et al. Prognostic value of grip strength: findings from the Prospective Urban Rural Epidemiology (PURE) study. Lancet. (2015) 386:266-73. doi: 10.1016/S0140-6736(14)62000-6

22. Taekema DG, Gussekloo J, Maier AB, Westendorp RGJ, de Craen AJM. Handgrip strength as a predictor of functional, psychological and social health. A prospective population-based study among the oldest old. Age Ageing. (2010) 39:331-7. doi: 10.1093/ageing/afq022

23. World Health Organization. Obesity: preventing and managing the global epidemic. Report of a WHO consultation. World Health Organ Tech Rep Ser. (2000) 894:i-xii, 1-253.

24. Jee SH, Sull JW, Park J, Lee S-Y, Ohrr H, Guallar E, et al. Body-mass index and mortality in Korean men and women. N Engl J Med. (2006) 355:779-87. doi: 10.1056/NEJMoa054017

25. World Health Organization. Regional Office for the Western Pacific. The Asia-Pacific Perspective: Redefining Obesity and Its Treatment: Sydney: Health Communications Australia. (2000). available online at: https://apps.who.int/ iris/handle/10665/206936

26. Després J-P. Body fat distribution and risk of cardiovascular disease: an update. Circulation. (2012) 126:1301-13. doi: 10.1161/CIRCULATIONAHA.111.067264

27. Garvey WT, Mechanick JI, Brett EM, Garber AJ, Hurley DL, Jastreboff AM, et al. American association of clinical endocrinologists and American college of endocrinology comprehensive clinical practice guidelines for medical care of patients with obesity. Endocr Pract. (2016) 22:1-203. doi: 10.4158/EP161365.GL

28. Alberti KGM, Zimmet P, Shaw J. The metabolic syndrome-a new worldwide definition. Lancet. (2005) 366:1059-62. doi: 10.1016/S0140-6736(05)67 402-8

29. Lee SY, Park HS, Kim DJ, Han JH, Kim SM, Cho GJ, et al. Appropriate waist circumference cutoff points for central obesity in Korean adults. Diabetes Res Clin Pract. (2007) 75:72-80. doi: 10.1016/j.diabres.2006.04.013 
30. Prado C, Wells J, Smith S, Stephan B, Siervo M. Sarcopenic obesity: a critical appraisal of the current evidence. Clin Nutr. (2012) 31:583-601. doi: 10.1016/j.clnu.2012.06.010

31. Batsis JA, Mackenzie TA, Lopez-Jimenez F, Bartels SJ. Sarcopenia, sarcopenic obesity, and functional impairments in older adults: national health and nutrition examination surveys 1999-2004. Nutr Res. (2015) 35:1031-9. doi: 10.1016/j.nutres.2015.09.003

32. Kim Y-S, Lee Y, Chung Y-S, Lee D-J, Joo N-S, Hong D, et al. Prevalence of sarcopenia and sarcopenic obesity in the Korean population based on the fourth Korean National health and nutritional examination surveys. $J$ Gerontol A Biol Sci Med Sci. (2012) 67:1107-13. doi: 10.1093/gerona/gls071

33. Hwang B, Lim J-Y, Lee J, Choi N-K, Ahn Y-O, Park B-J. Prevalence rate and associated factors of sarcopenic obesity in Korean elderly population. J Korean Med Sci. (2012) 27:748-55. doi: 10.3346/jkms.2012.27.7.748

34. Baumgartner RN, Wayne SJ, Waters DL, Janssen I, Gallagher D, Morley JE. Sarcopenic obesity predicts instrumental activities of daily living disability in the elderly. Obes Res. (2004) 12:1995-2004. doi: 10.1038/oby.2004.250

35. Hirani V, Naganathan V, Blyth F, Le Couteur DG, Seibel MJ, Waite LM, et al. Longitudinal associations between body composition, sarcopenic obesity and outcomes of frailty, disability, institutionalisation and mortality in community-dwelling older men: the concord health and ageing in men project. Age Ageing. (2017) 46:413-20. doi: 10.1093/ageing/afw214

36. Davison KK, Ford ES, Cogswell ME, Dietz WH. Percentage of body fat and body mass index are associated with mobility limitations in people aged 70 and older from NHANES III. J Am Geriatr Soc. (2002) 50:1802-9. doi: 10.1046/j.1532-5415.2002.50508.x

37. Zoico E, Di Francesco V, Guralnik J, Mazzali G, Bortolani A, Guariento S, et al. Physical disability and muscular strength in relation to obesity and different body composition indexes in a sample of healthy elderly women. Int J Obes Relat Metab Disord. (2004) 28:234-41. doi: 10.1038/sj.ijo.0802552

38. Stenholm S, Alley D, Bandinelli S, Griswold M, Koskinen S, Rantanen T, et al. The effect of obesity combined with low muscle strength on decline in mobility in older persons: results from the InCHIANTI study. Int J Obes. (2009) 33:635-44. doi: 10.1038/ijo.2009.62

39. Yang M, Jiang J, Hao Q, Luo L, Dong B. Dynapenic obesity and lower extremity function in elderly adults. J Am Med Dir Assoc. (2015) 16:31-6. doi: 10.1016/j.jamda.2014.06.019

40. Jung S, Yabushita N, Kim M, Seino S, Nemoto M, Osuka Y, et al. Obesity and muscle weakness as risk factors for mobility limitation in communitydwelling older Japanese women: a two-year follow-up investigation. J Nutr Health Aging. (2016) 20:28-34. doi: 10.1007/s12603-016-0672-7

41. Kim Y, White T, Wijndaele K, Sharp SJ, Wareham NJ, Brage S. Adiposity and grip strength as long-term predictors of objectively measured physical activity in 93015 adults: the UK biobank study. Int J Obes. (2017) 41:1361-8. doi: 10.1038/ijo.2017.122

42. Guralnik JM, Ferrucci L, Pieper CF, Leveille SG, Markides KS, Ostir GV, et al. Lower extremity function and subsequent disability: consistency across studies, predictive models, and value of gait speed alone compared with the short physical performance battery. J Gerontol A Biol Sci Med Sci. (2000) 55:M221-M31. doi: 10.1093/gerona/55.4.M221

43. Cesari M, Kritchevsky SB, Newman AB, Simonsick EM, Harris TB, Penninx BW, et al. Added value of physical performance measures in predicting adverse health-related events: results from the health, aging and body composition study. J Am Geriatr Soc. (2009) 57:251-9. doi: 10.1111/j.1532-5415.2008.02126.x

44. Cawthon PM, Fox KM, Gandra SR, Delmonico MJ, Chiou CF, Anthony MS, et al. Do muscle mass, muscle density, strength, and physical function similarly influence risk of hospitalization in older adults? J Am Geriatr Soc. (2009) 57:1411-9. doi: 10.1111/j.1532-5415.2009.02366.x

45. Akune T, Muraki S, Oka H, Tanaka S, Kawaguchi H, Tokimura F, et al. Incidence of certified need of care in the long-term care insurance system and its risk factors in the elderly of Japanese population-based cohorts: the ROAD study. Geriatr Gerontol Int. (2014) 14:695-701. doi: 10.1111/ggi.12155

46. Studenski S, Perera S, Wallace D, Chandler JM, Duncan PW, Rooney E, et al. Physical performance measures in the clinical setting. J Am Geriatr Soc. (2003) 51:314-22. doi: 10.1046/j.1532-5415.2003.51104.x

47. Cesari M, Kritchevsky SB, Penninx BW, Nicklas BJ, Simonsick EM, Newman $\mathrm{AB}$, et al. Prognostic value of usual gait speed in well-functioning older people-results from the health, aging and body composition study. J Am Geriatr Soc. (2005) 53:1675-80. doi: 10.1111/j.1532-5415.2005.53501.x

48. Montero-Odasso M, Schapira M, Soriano ER, Varela M, Kaplan R, Camera LA, et al. Gait velocity as a single predictor of adverse events in healthy seniors aged 75 years and older. J Gerontol A Biol Sci Med Sci. (2005) 60:1304-9. doi: 10.1093/gerona/60.10.1304

49. Cawthon PM, Lui L-Y, Taylor BC, McCulloch CE, Cauley JA, Lapidus J, et al. Clinical definitions of sarcopenia and risk of hospitalization in communitydwelling older men: the osteoporotic fractures in men study. J Gerontol A Biol Sci Med Sci. (2017) 72:1383-9. doi: 10.1093/gerona/glw327

50. Cawthon PM, Lui LY, McCulloch CE, Cauley JA, Paudel ML, Taylor B, et al. Sarcopenia and health care utilization in older women. J Gerontol A Biol Sci Med Sci. (2017) 72:95-101. doi: 10.1093/gerona/glw118

51. Zizza CA, Herring A, Stevens J, Popkin BM. Obesity affects nursing-care facility admission among whites but not blacks. Obes Res. (2002) 10:816-23. doi: 10.1038 /oby.2002.110

52. Elkins JS, Whitmer RA, Sidney S, Sorel M, Yaffe K, Johnston SC. Midlife obesity and long-term risk of nursing home admission. Obesity. (2006) 14:1472-8. doi: 10.1038/oby.2006.167

53. Valiyeva E, Russell LB, Miller JE, Safford MM. Lifestyle-related risk factors and risk of future nursing home admission. Arch Intern Med. (2006) 166:985-90. doi: 10.1001/archinte.166.9.985

54. Wannamethee SG, Shaper AG, Lennon L, Whincup PH. Decreased muscle mass and increased central adiposity are independently related to mortality in older men. Am J Clin Nutr. (2007) 86:1339-46. doi: 10.1093/ajcn/86.5.1339

55. Atkins JL, Whincup PH, Morris RW, Lennon LT, Papacosta O, Wannamethee SG. Sarcopenic obesity and risk of cardiovascular disease and mortality: a population-based cohort study of older men. J Am Geriatr Soc. (2014) 62:253-60. doi: 10.1111/jgs.12652

56. Batsis J, Mackenzie T, Barre L, Lopez-Jimenez F, Bartels SJ. Sarcopenia, sarcopenic obesity and mortality in older adults: results from the national health and nutrition examination survey III. Eur J Clin Nutr. (2014) 68:10017. doi: $10.1038 /$ ejcn.2014.117

57. Cesari M, Pahor M, Lauretani F, Zamboni V, Bandinelli S, Bernabei R, et al. Skeletal muscle and mortality results from the InCHIANTI study. J Gerontol A Biol Sci Med Sci. (2009) 64:377-84. doi: 10.1093/gerona/gln031

58. Sanada K, Chen R, Willcox B, Ohara T, Wen A, Takenaka C, et al. Association of sarcopenic obesity predicted by anthropometric measurements and 24$\mathrm{y}$ all-cause mortality in elderly men: the kuakini honolulu heart program. Nutrition. (2018) 46:97-102. doi: 10.1016/j.nut.2017.09.003

59. Newman AB, Haggerty CL, Goodpaster B, Harris T, Kritchevsky S, Nevitt $\mathrm{M}$, et al. Strength and muscle quality in a well-functioning cohort of older adults: the health, aging and body composition study. J Am Geriatr Soc. (2003) 51:323-30. doi: 10.1046/j.1532-5415.2003.51105.x

60. Metter EJ, Lynch N, Conwit R, Lindle R, Tobin J, Hurley B. Muscle quality and age: cross-sectional and longitudinal comparisons. J Gerontol A Biol Sci Med Sci. (1999) 54:B207-18. doi: 10.1093/gerona/54.5.B207

61. Ling CH, Taekema D, De Craen AJ, Gussekloo J, Westendorp RG, Maier AB. Handgrip strength and mortality in the oldest old population: the Leiden 85-plus study. CMAJ. (2010) 182:429-35. doi: 10.1503/cmaj.091278

62. Rijk JM, Roos PR, Deckx L, van den Akker M, Buntinx F. Prognostic value of handgrip strength in people aged 60 years and older: a systematic review and meta-analysis. Geriatr Gerontol Int. (2016) 16:5-20. doi: 10.1111/ggi. 12508

63. Sasaki H, Kasagi F, Yamada M, Fujita S. Grip strength predicts cause-specific mortality in middle-aged and elderly persons. Am J Med. (2007) 120:337-42. doi: 10.1016/j.amjmed.2006.04.018

64. Strand BH, Cooper R, Bergland A, Jørgensen L, Schirmer H, Skirbekk $\mathrm{V}$, et al. The association of grip strength from midlife onwards with all-cause and cause-specific mortality over 17 years of follow-up in the tromsø study. J Epidemiol Commun Health. (2016) 70:1214-21. doi: 10.1136/jech-2015-206776

65. Oksuzyan A, Demakakos P, Shkolnikova M, Thinggaard M, Vaupel JW, Christensen K, et al. Handgrip strength and its prognostic value for mortality in Moscow, Denmark, and England. PLoS ONE. (2017) 12:e0182684. doi: 10.1371/journal.pone.0182684

66. Wu Y, Wang W, Liu T, Zhang D. Association of grip strength with risk of allcause mortality, cardiovascular diseases, and cancer in community-dwelling 
populations: a meta-analysis of prospective cohort studies. J Am Med Dir Assoc. (2017) 18:551. e17-35. doi: 10.1016/j.jamda.2017.03.011

67. Rantanen T, Harris T, Leveille SG, Visser M, Foley D, Masaki K, et al. Muscle strength and body mass index as long-term predictors of mortality in initially healthy men. J Gerontol A Biol Sci Med Sci. (2000) 55:M168-73. doi: 10.1093/gerona/55.3.M168

68. Liu L-K, Chen L-Y, Yeh K-P, Lin M-H, Hwang A-C, Peng L-N, et al. Sarcopenia, but not sarcopenic obesity, predicts mortality for older old men: a 3-year prospective cohort study. J Clin Gerontol Geriatr. (2014) 5:42-6. doi: 10.1016/j.jcgg.2014.01.002

69. Stenholm S, Mehta NK, Elo IT, Heliövaara M, Koskinen S, Aromaa A. Obesity and muscle strength as long-term determinants of all-cause mortality-a 33-year follow-up of the mini-finland health examination survey. Int J Obes. (2014) 38:1126-32. doi: 10.1038/ijo.2013.214

70. Hamer M, O’Donovan G. Sarcopenic obesity, weight loss, and mortality: the english longitudinal study of ageing. Am J Clin Nutr. (2017) 106:125-9. doi: 10.3945/ajen.117.152488

71. Chen Y, Copeland WK, Vedanthan R, Grant E, Lee JE, Gu D, et al. Association between body mass index and cardiovascular disease mortality in east Asians and south Asians: pooled analysis of prospective data from the Asia cohort consortium. BMJ. (2013) 347:f5446. doi: 10.1136/bmj.f5446

72. Prospective Studies Collaboration, Whitlock G, Lewington S, Sherliker P, Clarke R, Emberson J, et al. Body-mass index and cause-specific mortality in 900000 adults: collaborative analyses of 57 prospective studies. Lancet. (2009) 373:1083-96. doi: 10.1016/S0140-6736(09)60318-4

73. Di Angelantonio E, Bhupathiraju SN, Wormser D, Gao P, Kaptoge S, de Gonzalez $\mathrm{AB}$, et al. Body-mass index and all-cause mortality: individualparticipant-data meta-analysis of 239 prospective studies in four continents. Lancet. (2016) 388:776-86. doi: 10.1016/S0140-6736(16)30175-1

74. Bhaskaran K, dos-Santos-Silva I, Leon DA, Douglas IJ, Smeeth L. Association of BMI with overall and cause-specific mortality: a population-based cohort study of 3. 6 million adults in the UK. Lancet Diabetes Endocrinol. (2018) 6:944-53. doi: 10.1016/S2213-8587(18)30288-2

75. Romero-Corral A, Montori VM, Somers VK, Korinek J, Thomas RJ, Allison TG, et al. Association of bodyweight with total mortality and with cardiovascular events in coronary artery disease: a systematic review of cohort studies. Lancet. (2006) 368:666-78. doi: 10.1016/S0140-6736(06)69251-9

76. Miller S, Wolfe RR. The danger of weight loss in the elderly. J Nutr Health Aging. (2008) 12:487-91. doi: 10.1007/BF02982710

77. Dumurgier J, Elbaz A, Ducimetiere P, Tavernier B, Alperovitch A, Tzourio C. Slow walking speed and cardiovascular death in well functioning older adults: prospective cohort study. BMJ. (2009) 339:b4460. doi: 10.1136/bmj.b4460

78. Studenski S, Perera S, Patel K, Rosano C, Faulkner K, Inzitari M, et al. Gait speed and survival in older adults. JAMA. (2011) 305:50-8. doi: 10.1001/jama.2010.1923

79. Pavasini R, Guralnik J, Brown JC, di Bari M, Cesari M, Landi F, et al. Short physical performance battery and all-cause mortality: systematic review and meta-analysis. BMC Med. (2016) 14:215. doi: 10.1186/s12916-016-0763-7

80. Veronese N, Stubbs B, Fontana L, Trevisan C, Bolzetta F, Rui MD, et al. A comparison of objective physical performance tests and future mortality in the elderly people. J Gerontol A Biol Sci Med Sci. (2016) 72:362-8. doi: 10.1093/gerona/glw139

81. Zamboni M, Mazzali G, Fantin F, Rossi A, Di Francesco V. Sarcopenic obesity: a new category of obesity in the elderly. Nutr Metab Cardiovasc Dis. (2008) 18:388-95. doi: 10.1016/j.numecd.2007.10.002

82. Wannamethee SG, Atkins JL. Muscle loss and obesity: the health implications of sarcopenia and sarcopenic obesity. Proc Nutr Soc. (2015) 74:405-12. doi: 10.1017/S002966511500169X

83. Kohara K. Sarcopenic obesity in aging population: current status and future directions for research. Endocrine. (2014) 45:15-25. doi: 10.1007/s12020-013-9992-0

84. Kim TN, Choi KM. The implications of sarcopenia and sarcopenic obesity on cardiometabolic disease. J Cell Biochem. (2015) 116:1171-8. doi: $10.1002 /$ jcb. 25077

85. Choi KM. Sarcopenia and sarcopenic obesity. Korean J Intern Med. (2016) 31:1054-60. doi: 10.3904/kjim.2016.193
86. Srikanthan P, Hevener AL, Karlamangla AS. Sarcopenia exacerbates obesityassociated insulin resistance and dysglycemia: findings from the National health and nutrition examination survey III. PLoS ONE. (2010) 5:e10805. doi: 10.1371/journal.pone.0010805

87. Kim TN, Park MS, Lim KI, Choi HY, Yang SJ, Yoo HJ, et al. Relationships between sarcopenic obesity and insulin resistance, inflammation, and vitamin D status: the Korean sarcopenic obesity study. Clin Endocrinol. (2013) 78:525-32. doi: 10.1111/j.1365-2265.2012.04433.x

88. Chung J-Y, Kang H-T, Lee D-C, Lee H-R, Lee Y-J. Body composition and its association with cardiometabolic risk factors in the elderly: a focus on sarcopenic obesity. Arch Gerontol Geriatr. (2013) 56:270-8. doi: 10.1016/j.archger.2012.09.007

89. Lim S, Kim JH, Yoon JW, Kang SM, Choi SH, Park YJ, et al. Sarcopenic obesity: prevalence and association with metabolic syndrome in the Korean longitudinal study on health and aging (KLoSHA). Diabetes Care. (2010) 33:1652-4. doi: 10.2337/dc10-0107

90. Lu C-W, Yang K-C, Chang H-H, Lee L-T, Chen C-Y, Huang K-C. Sarcopenic obesity is closely associated with metabolic syndrome. Obes Res Clin Pract. (2013) 7:e301-7. doi: 10.1016/j.orcp.2012.02.003

91. Scott D, Park MS, Kim TN, Ryu JY, Hong HC, Yoo HJ, et al. Associations of low muscle mass and the metabolic syndrome in caucasian and Asian middle-aged and older adults. J Nutr Health Aging. (2016) 20:248-55. doi: 10.1007/s12603-015-0559-z

92. Baek S, Nam G, Han K, Choi S, Jung S, Bok A, et al. Sarcopenia and sarcopenic obesity and their association with dyslipidemia in Korean elderly men: the 2008-2010 Korea National health and nutrition examination survey. J Endocrinol Invest. (2014) 37:247-60. doi: 10.1007/s40618-013-0011-3

93. Lim H-S, Park Y-H, Suh K, Yoo MH, Park HK, Kim HJ, et al. Association between sarcopenia, sarcopenic obesity, and chronic disease in Korean elderly. J Bone Metab. (2018) 25:187-93. doi: 10.11005/jbm.2018.25.3.187

94. Kim J-H, Cho JJ, Park YS. Relationship between sarcopenic obesity and cardiovascular disease risk as estimated by the Framingham risk score. $J$ Korean Med Sci. (2015) 30:264-71. doi: 10.3346/jkms.2015.30.3.264

95. Chin SO, Rhee SY, Chon S, Hwang Y-C, Jeong I-K, Oh S, et al. Sarcopenia is independently associated with cardiovascular disease in older Korean adults: the Korea National health and nutrition examination survey (KNHANES) from (2009). PLoS ONE. (2013) 8:e60119. doi: 10.1371/journal.pone.00 60119

96. Messier V, Karelis AD, Lavoie M-E, Brochu M, Faraj M, Strychar I, et al. Metabolic profile and quality of life in class I sarcopenic overweight and obese postmenopausal women: a MONET study. Appl Physiol Nutr Metab. (2009) 34:18-24. doi: 10.1139/H08-135

97. Aubertin-Leheudre M, Lord C, Goulet ED, Khalil A, Dionne IJ. Effect of sarcopenia on cardiovascular disease risk factors in obese postmenopausal women. Obesity. (2006) 14:2277-83. doi: 10.1038/oby.2006.267

98. Yi D, Khang AR, Lee HW, Son SM, Kang YH. Relative handgrip strength as a marker of metabolic syndrome: the Korea National health and nutrition examination survey (KNHANES) VI (2014-2015). Diabetes Metab Syndr Obes. (2018) 11:227-40. doi: 10.2147/DMSO.S166875

99. Ji C, Zheng L, Zhang R, Wu Q, Zhao Y. Handgrip strength is positively related to blood pressure and hypertension risk: results from the National Health and nutrition examination survey. Lipids Health Dis. (2018) 17:86. doi: 10.1186/s12944-018-0734-4

100. Li D, Guo G, Xia L, Yang X, Zhang B, Liu F, et al. Relative handgrip strength is inversely associated with metabolic profile and metabolic disease in the general population in China. Front Physiol. (2018) 9:59. doi: 10.3389/fphys.2018.00059

101. Lee M-R, Jung SM, Bang H, Kim HS, Kim YB. Association between muscle strength and type 2 diabetes mellitus in adults in Korea: data from the Korea national health and nutrition examination survey (KNHANES) VI. Medicine. (2018) 97:e10984. doi: 10.1097/MD.0000000000010984

102. Kim B-J, Ahn SH, Lee SH, Hong S, Hamrick MW, Isales CM, et al. Lower hand grip strength in older adults with non-alcoholic fatty liver disease: a nationwide population-based study. Aging. (2019) 11:4547-60. doi: 10.18632/aging.102068

103. Kim GR, Sun J, Han M, Park S, Nam CM. Impact of handgrip strength on cardiovascular, cancer and all-cause mortality in the 
Korean longitudinal study of ageing. BMJ Open. (2019) 9:e027019. doi: 10.1136/bmjopen-2018-027019

104. Cuthbertson DJ, Bell JA, Ng SY, Kemp GJ, Kivimaki M, Hamer M. Dynapenic obesity and the risk of incident Type 2 diabetes: the english longitudinal study of ageing. Diabet Med. (2016) 33:1052-9. doi: 10.1111/dme.12991

105. Stephen W, Janssen I. Sarcopenic-obesity and cardiovascular disease risk in the elderly. $J$ Nutr Health Aging. (2009) 13:460-6. doi: 10.1007/s12603-009-0084-z

106. Dumurgier J, Elbaz A, Dufouil C, Tavernier B, Tzourio C. Hypertension and lower walking speed in the elderly: the three-City study. J Hypertens. (2010) 28:1506-14. doi: 10.1097/HJH.0b013e328338bbec

107. Brach JS, Talkowski JB, Strotmeyer ES, Newman AB. Diabetes mellitus and gait dysfunction: possible explanatory factors. Phys Ther. (2008) 88:1365-74. doi: 10.2522/ptj.20080016

108. Elbaz A, Shipley MJ, Nabi H, Brunner EJ, Kivimaki M, Singh-Manoux A. Trajectories of the Framingham general cardiovascular risk profile in midlife and poor motor function later in life: the whitehall II study. Int J Cardiol. (2014) 172:96-102. doi: 10.1016/j.ijcard.2013.12.051

109. Szulc P, Beck TJ, Marchand F, Delmas PD. Low skeletal muscle mass is associated with poor structural parameters of bone and impaired balance in elderly men-the MINOS study. J Bone Miner Res. (2005) 20:721-9. doi: 10.1359/JBMR.041230

110. Moreland JD, Richardson JA, Goldsmith CH, Clase CM. Muscle weakness and falls in older adults: a systematic review and meta-analysis. J Am Geriatr Soc. (2004) 52:1121-9. doi: 10.1111/j.1532-5415.2004.52310.x

111. Landi F, Liperoti R, Russo A, Giovannini S, Tosato M, Capoluongo E, et al. Sarcopenia as a risk factor for falls in elderly individuals: results from the ilSIRENTE study. Clin Nutr. (2012) 31:652-8. doi: 10.1016/j.clnu.2012.02.007

112. Scott D, Sanders KM, Aitken D, Hayes A, Ebeling PR, Jones G. Sarcopenic obesity and dynapenic obesity: 5 -year associations with falls risk in middleaged and older adults. Obesity. (2014) 22:1568-74. doi: 10.1002/oby.20734

113. Pereira JC, de Moraes Elias J, Neri SG, Gadelha AB, Lemos RR, Lima RM. Dynapenic abdominal obesity as a risk factor for falls in older women. Top Geriatr Rehabil. (2019) 35:149-55. doi: 10.1097/TGR.0000000000000225

114. Lee S, Kim TN, Kim SH. Sarcopenic obesity is more closely associated with knee osteoarthritis than is nonsarcopenic obesity: a cross-sectional study. Arthritis Rheum. (2012) 64:3947-54. doi: 10.1002/art.37696

115. Chung JH, Hwang HJ, Shin H-Y, Han CH. Association between sarcopenic obesity and bone mineral density in middle-aged and elderly Korean. Ann Nutr Metab. (2016) 68:77-84. doi: 10.1159/000442004

116. Scott D, Chandrasekara SD, Laslett LL, Cicuttini F, Ebeling PR, Jones G. Associations of sarcopenic obesity and dynapenic obesity with bone mineral density and incident fractures over 5-10 years in community-dwelling older adults. Calcif Tissue Int. (2016) 99:30-42. doi: 10.1007/s00223-016-0123-9

117. Hamer M, Batty GD, Kivimaki M. Sarcopenic obesity and risk of new onset depressive symptoms in older adults: english longitudinal study of ageing. Int J Obes. (2015) 39:1717-20. doi: 10.1038/ijo.2015.124

118. Ishii S, Chang C, Tanaka $\mathrm{T}$, Kuroda A, Tsuji T, Akishita M, et al. The association between sarcopenic obesity and depressive symptoms in older Japanese adults. PLoS ONE. (2016) 11:e0162898. doi: 10.1371/journal.pone. 0162898

119. Hong SH, Choi KM. Sarcopenic obesity, insulin resistance, and their implications in cardiovascular and metabolic consequences. Int J Mol Sci. (2020) 21:E494. doi: 10.3390/ijms21020494

120. Gallagher D, Belmonte D, Deurenberg P, Wang Z, Krasnow N, PiSunyer FX, et al. Organ-tissue mass measurement allows modeling of REE and metabolically active tissue mass. Am J Physiol. (1998) 275:E249-58. doi: 10.1152/ajpendo.1998.275.2.E249

121. Astrup A, Gotzsche PC, van de Werken K, Ranneries C, Toubro S, Raben A, et al. Meta-analysis of resting metabolic rate in formerly obese subjects. Am J Clin Nutr. (1999) 69:1117-22. doi: 10.1093/ajcn/69.6.1117

122. Abizanda P, Romero L, Sánchez-Jurado PM, Ruano TF, Ríos SS, Sánchez MF. Energetics of aging and frailty: the FRADEA study. J Gerontol A Biol Sci Med Sci. (2015) 71:787-96. doi: 10.1093/gerona/glv182

123. McPhee JS, French DP, Jackson D, Nazroo J, Pendleton N, Degens H. Physical activity in older age: perspectives for healthy ageing and frailty. Biogerontology. (2016) 17:567-80. doi: 10.1007/s10522-016-9641-0
124. Conley KE, Jubrias SA, Esselman PC. Oxidative capacity and ageing in human muscle. J Physiol. (2000) 526(Pt 1):203-10. doi: 10.1111/j.1469-7793.2000.t01-1-00203.x

125. Cartwright MJ, Tchkonia T, Kirkland JL. Aging in adipocytes: potential impact of inherent, depot-specific mechanisms. Exp Gerontol. (2007) 42:46371. doi: 10.1016/j.exger.2007.03.003

126. Lovejoy JC, Champagne CM, de Jonge L, Xie H, Smith SR. Increased visceral fat and decreased energy expenditure during the menopausal transition. Int J Obes. (2008) 32:949-58. doi: 10.1038/ijo.2008.25

127. Sowers M, Zheng H, Tomey K, Karvonen-Gutierrez C, Jannausch M, Li $\mathrm{X}$, et al. Changes in body composition in women over six years at midlife: ovarian and chronological aging. J Clin Endocrinol Metab. (2007) 92:895901. doi: 10.1210/jc.2006-1393

128. Schaap LA, Pluijm SM, Smit JH, van Schoor NM, Visser M, Gooren LJ, et al. The association of sex hormone levels with poor mobility, low muscle strength and incidence of falls among older men and women. Clin Endocrinol. (2005) 63:152-60. doi: 10.1111/j.1365-2265.2005.02315.x

129. O’Donnell AB, Travison TG, Harris SS, Tenover JL, McKinlay JB. Testosterone, dehydroepiandrosterone, and physical performance in older men: results from the massachusetts male aging study. J Clin Endocrinol Metab. (2006) 91:425-31. doi: 10.1210/jc.2005-1227

130. Iannuzzi-Sucich $M$, Prestwood KM, Kenny AM. Prevalence of sarcopenia and predictors of skeletal muscle mass in healthy, older men and women. J Gerontol A Biol Sci Med Sci. (2002) 57:M772-7. doi: $10.1093 /$ gerona/57.12.M772

131. Gruenewald DA, Matsumoto AM. Testosterone supplementation therapy for older men: potential benefits and risks. J Am Geriatr Soc. (2003) 51:101-15; discussion: 15. doi: 10.1034/j.1601-5215.2002.51018.x

132. Isidori AM, Giannetta E, Greco EA, Gianfrilli D, Bonifacio V, Isidori A, et al. Effects of testosterone on body composition, bone metabolism and serum lipid profile in middle-aged men: a meta-analysis. Clin Endocrinol. (2005) 63:280-93. doi: 10.1111/j.1365-2265.2005.02339.x

133. Ferrando AA, Sheffield-Moore M, Yeckel CW, Gilkison C, Jiang J, Achacosa A, et al. Testosterone administration to older men improves muscle function: molecular and physiological mechanisms. Am J Physiol Endocrinol Metab. (2002) 282:E601-7. doi: 10.1152/ajpendo.00362.2001

134. Page ST, Amory JK, Bowman FD, Anawalt BD, Matsumoto AM, Bremner WJ, et al. Exogenous testosterone (T) alone or with finasteride increases physical performance, grip strength, and lean body mass in older men with low serum T. J Clin Endocrinol Metab. (2005) 90:1502-10. doi: 10.1210/jc.2004-1933

135. Srinivas-Shankar U, Roberts SA, Connolly MJ, O'Connell MDL, Adams JE, Oldham JA, et al. Effects of testosterone on muscle strength, physical function, body composition, and quality of life in intermediate-frail and frail elderly men: a randomized, double-blind, placebo-controlled study. J Clin Endocrinol Metab. (2010) 95:639-50. doi: 10.1210/jc.2009-1251

136. Ottenbacher KJ, Ottenbacher ME, Ottenbacher AJ, Acha AA, Ostir GV. Androgen treatment and muscle strength in elderly men: a meta-analysis. J Am Geriatr Soc. (2006) 54:1666-73. doi: 10.1111/j.1532-5415.2006.00 938.x

137. Emmelot-Vonk MH, Verhaar HJ, Nakhai Pour HR, Aleman A, Lock TM, Bosch JL, et al. Effect of testosterone supplementation on functional mobility, cognition, and other parameters in older men: a randomized controlled trial. JAMA. (2008) 299:39-52. doi: 10.1001/jama.2007.51

138. Laurent MR, Antonio L, Vanderschueren D. Testosterone treatment in older men. N Engl J Med. (2016) 375:89-90. doi: 10.1056/NEJMc1603665

139. Batsis JA, Villareal DT. Sarcopenic obesity in older adults: aetiology, epidemiology and treatment strategies. Nat Rev Endocrinol. (2018) 14:51337. doi: 10.1038/s41574-018-0062-9

140. El Bizri I, Batsis JA. Linking epidemiology and molecular mechanisms in sarcopenic obesity in populations. Proc Nutr Soc. (2020) 14:1-9. doi: $10.1017 /$ S0029665120000075

141. Kalinkovich A, Livshits G. Sarcopenic obesity or obese sarcopenia: a cross talk between age-associated adipose tissue and skeletal muscle inflammation as a main mechanism of the pathogenesis. Ageing Res Rev. (2017) 35:200-21. doi: 10.1016/j.arr.2016.09.008

142. Visser M, Goodpaster BH, Kritchevsky SB, Newman AB, Nevitt M, Rubin $\mathrm{SM}$, et al. Muscle mass, muscle strength, and muscle fat infiltration as predictors of incident mobility limitations in well-functioning older persons. 
J Gerontol A Biol Sci Med Sci. (2005) 60:324-33. doi: 10.1093/gerona/60. 3.324

143. Addison O, Marcus RL, Lastayo PC, Ryan AS. Intermuscular fat: a review of the consequences and causes. Int J Endocrinol. (2014) 2014:309570. doi: $10.1155 / 2014 / 309570$

144. Akhmedov D, Berdeaux R. The effects of obesity on skeletal muscle regeneration. Front Physiol. (2013) 4:371. doi: 10.3389/fphys.2013.00371

145. Marzetti E, Calvani R, Cesari M, Buford TW, Lorenzi M, Behnke BJ, et al. Mitochondrial dysfunction and sarcopenia of aging: from signaling pathways to clinical trials. Int J Biochem Cell Biol. (2013) 45:2288-301. doi: 10.1016/j.biocel.2013.06.024

146. Tumova J, Andel M, Trnka J. Excess of free fatty acids as a cause of metabolic dysfunction in skeletal muscle. Physiol Res. (2016) 65:193-207. doi: 10.33549/physiolres. 932993

147. Carnio S, LoVerso F, Baraibar MA, Longa E, Khan MM, Maffei $\mathrm{M}$, et al. Autophagy impairment in muscle induces neuromuscular junction degeneration and precocious aging. Cell Rep. (2014) 8:1509-21. doi: 10.1016/j.celrep.2014.07.061

148. Wensveen FM, Valentic S, Sestan M, Turk Wensveen T, Polic B. The "Big Bang" in obese fat: events initiating obesity-induced adipose tissue inflammation. Eur J Immunol. (2015) 45:2446-56. doi: 10.1002/eji.201545502

149. Exley MA, Hand L, O'Shea D, Lynch L. Interplay between the immune system and adipose tissue in obesity. J Endocrinol. (2014) 223:R41-8. doi: 10.1530/JOE-13-0516

150. Tateya S, Kim F, Tamori Y. Recent advances in obesity-induced inflammation and insulin resistance. Front Endocrinol. (2013) 4:93. doi: $10.3389 /$ fendo.2013.00093
151. Procaccini C, Jirillo E, Matarese G. Leptin as an immunomodulator. Mol Aspects Med. (2012) 33:35-45. doi: 10.1016/j.mam.2011.10.012

152. Sente $T$, van Berendoncks AM, Fransen E, Vrints CJ, Hoymans VY. Tumor necrosis factor-alpha impairs adiponectin signalling, mitochondrial biogenesis, and myogenesis in primary human myotubes cultures. Am J Physiol Heart Circ Physiol. (2016) 310:H1164-75. doi: 10.1152/ajpheart.00831.2015

153. Yeap BB, Paul Chubb SA, Lopez D, Ho KK, Hankey GJ, Flicker L. Associations of insulin-like growth factor-I and its binding proteins and testosterone with frailty in older men. Clin Endocrinol. (2013) 78:752-9. doi: 10.1111/cen.12052

154. Beaudart C, Rolland Y, Cruz-Jentoft AJ, Bauer JM, Sieber C, Cooper $\mathrm{C}$, et al. Assessment of muscle function and physical performance in daily clinical practice : a position paper endorsed by the European society for clinical and economic aspects of osteoporosis, osteoarthritis and musculoskeletal diseases (ESCEO). Calcif Tissue Int. (2019) 105:1-14. doi: 10.1007/s00223-019-00545-w

Conflict of Interest: The authors declare that the research was conducted in the absence of any commercial or financial relationships that could be construed as a potential conflict of interest.

Copyright $(02020$ Roh and Choi. This is an open-access article distributed under the terms of the Creative Commons Attribution License (CC BY). The use, distribution or reproduction in other forums is permitted, provided the original author $(s)$ and the copyright owner(s) are credited and that the original publication in this journal is cited, in accordance with accepted academic practice. No use, distribution or reproduction is permitted which does not comply with these terms. 